\title{
El Otro y la diNÁMica de la fantasía EN LA AUTOLESIÓN CUTÁNEA
}

\section{The 'Other' and the Dynamic of Fantasy in Skin Self-Harm}

\section{Andrés Felipe Rojas-Zapata ${ }^{1}$, Orlando Lenin Enríquez-Eraso², Gilberto Carvajal-Guzmán ${ }^{3}$}

https://doi.org/10.17533/ udea.rp.v12n1a09

\section{Resumen}

Este artículo de investigación tuvo como objetivo analizar el lugar que ocupa el Otro en la fantasía que se genera en torno a las autolesiones cutáneas (cutting) en una adolescente que presenta este comportamiento. La metodología se guio por el paradigma cualitativo de investigación, la investigación psicoanalítica con propósitos cognoscitivos y el estudio de caso. Para recolectar la información se llevaron a cabo entrevistas individuales a profundidad y se aplicó la técnica del análisis del discurso. En los resultados y la discusión

\section{Abstract}

This paper had the aim of analyzing the role of the Other in the fantasy that appears around self-harm (cutting) in a teenager who presents

Recibido: 2019-11-29 / Aceptado: 2020-05-07

Para citar este artículo en APA: Rojas-Zapata, A., Enríquez-Eraso, O., y Carvajal-Guzmán, G. (2020). El Otro y la dinámica de la fantasía en la autolesión cutánea. Revista de Psicología Universidad de Antioquia, 12(1), 179-202. doi: https://doi. org/10.17533/ udea.rp.v12n1a09 se describe cómo la autolesión es producto de los significados que el sujeto elabora frente a las dificultades familiares que ha vivido; en este caso, los cortes en la piel, en su fantasía, son un medio para obtener la atención del Otro, dejar de posicionarse como objeto de rechazo $y$, en consecuencia, ser reconocida como sujeto.

Palabras clave: adolescencia, comportamiento autolesivo, cutting, fantasía, lesión.

this behavior. The methodology was guided by a qualitative research paradigm, psychoanalytic research with cognitive purpose, and

\footnotetext{
Psicólogo, Magíster en Docencia Universitaria. Docente Corporación Universitaria Minuto de Dios, Pasto, Colombia. Correo: arojaszapat@ uniminuto.edu.co; https://orcid.org/0000-0001 $-8275-3396$

2 Psicólogo, Magíster en Etnoliteratura. Docente Universidad de Nariño, Pasto, Colombia. Correo: orlando.lenin@gmail.com; https://orcid. org/0000-0002-1723-6402

3 Psicólogo, Magíster en Docencia Universitaria. Docente Universidad de Narińo, Pasto, Colombia. Correo: gcarvajalg@yahoo.es; https://orcid. org/0000-0003-4800-6682
} 
case study. For gathering the information, this paper carried out in-depth individual interviews and it applied the analysis of discourse technique. In the results and discussion is described how self-harm is the result of the meanings that the subject elaborates based on family difficulties; in this case, their skin cuts in her fantasy are a means to obtain the attention of the Other, stop being positioned as a rejection object, and in consequence be recognized like a subject.

Keywords: adolescence, self-injurious behavior, cutting, fantasy, injury.

\section{Introducción}

La adolescencia, según Manca (2011), es un periodo del desarrollo evolutivo en el que el sujeto busca alcanzar una autodefinición o autoconcepto, por lo que en esta etapa existe una tendencia al acting, es decir, a experimentar nuevas vivencias que le permitan crear una imagen de quién es él. Esto puede ayudar al sujeto a solucionar algunos conflictos subjetivos; no obstante, la búsqueda de identidad también puede conducirlo a realizar conductas peligrosas, como el consumo de alcohol y otras drogas, manejar en estado de embriaguez, o a iniciarse en prácticas de ataque al propio cuerpo socialmente aceptadas (por ejemplo, perforaciones [piercings] y tatuajes).

Esta misma autora señala que en algunos casos los adolescentes pueden llegar a presentar conductas autodestructivas, entre otras, realizándose marcas y cicatrices indelebles en la piel, que son una forma de expresión simbólica, del lenguaje, y pueden cumplir con diferentes funciones, como demarcar independencia afectiva con los padres, exteriorizar sentimientos negativos, reforzar la autoimagen, dar alivio a malestares subjetivos, etc. Entre estas formas de agresión se encuentran las autolesiones superficiales o moderadas en la piel, es decir, las autolesiones cutáneas con objetos corto-punzantes (cutting); autoagresión que consiste en realizar una automutilación deliberada en el tejido corporal sin la intención de suicidarse (Favazza, 1998).

Con respecto a la manifestación de este fenómeno, un estudio realizado con 1582 adolescentes, con edades entre los 12 y 18 años, encontró que el $13.71 \%$ refiere haberse autolesionado en algún momento de su vida (Baetens, Claes, Muehlenkamp, Grietens y Onghena, 2011). Ulloa, Hernández, Paniagua y Figueroa (2013), en otro trabajo realizado en México, con una muestra de 556 expedientes clínicos de adolescentes que han presentado autolesiones, encon- 
traron que el $76.30 \%$ corresponde a población femenina; además, se resalta que el $70 \%$ de las autolesiones se realizaron principalmente a través de cortes en las muñecas y los antebrazos. En una investigación más reciente realizada en este mismo país, Mayer, Morales, Figueroa y Ulloa (2016), en una muestra de 175 adolescentes, encontraron que el 27.9\% reportaron autolesionarse, con una relación mujer-hombre de 2:1; de esta población el 77.7\% refirió hacerlo a través de cortes en la piel, mientras que el 23.3\% restante lo hace a través de autoinfligirse golpes, pellizcos, quemaduras y de la ingesta de fármacos.

Para el caso de Colombia se tiene que, durante un periodo de observación comprendido entre los años 2009 a 2015, las conductas autolesivas se presentaron mayormente entre personas de 15 a 19 ańos de edad, correspondiendo el $29.7 \%$ a la población que se ha autolesionado; en esta, por cada hombre cuatro mujeres lo hacen. Además, se encuentra que el 20\% de las personas que se han autoinfligido daño lo han realizado con un arma cortopunzante (Ministerio de Salud, 2018).

Existen diferentes modelos que buscan explicar las causas que llevan a un adolescente a realizarse autolesiones cutáneas. Greydanus y Omar (2017) aducen que este comportamiento se presenta principalmente en mujeres, en las que se identifican dos características particulares: conductas o pensamientos autodegradantes y dificultad para regular las emociones, siendo las autolesiones una forma de buscar ayuda, expresar disgusto o enojo hacia sí mismo, además de estar relacionadas con pensamientos suicidas recurrentes y episodios disociativos.

Por lo que se refiere a la llegada a la adolescencia, Zamorano y Rojas (2017) describen que esta implica una lucha tanto para el adolescente como para su familia, dado que al superar la infancia también se culmina una etapa de la relación familiar y el adolescente empieza a hacer cuestionamientos que pueden manifestarse como un desafío hacia los padres; la forma en que estos respondan a las preguntas sobre la dinámica y la historia familiar influirá en el modo en que el adolescente resuelva sus conflictos emocionales; así, una respuesta autoritaria o negativa puede generar frustración e incrementar la posibilidad de realizarse cortes como una forma de representar eso que no se puede enunciar con palabras dentro de la historia familiar. 
Albores-Gallo et al. (2014) y Flores, Hernández, Navarrete y Figueroa (2013) expresan que otras causas para que los adolescentes se realicen autolesiones son sufrir de ansiedad, depresión, abusar de sustancias psicoactivas, el ser o haber sido víctima de acoso escolar, de abuso físico o sexual, la disfunción familiar y la autopercepción negativa sobre el propio cuerpo, lo cual está acompañado de ideas alusivas a que este comportamiento es un método para liberarse de dificultades personales, sentimientos negativos sobre sí mismo, desesperación, o para autocastigarse y causar temor en otros.

Respecto a lo anterior, Carvajal, Arancibia, Díaz, Mendoza y Salgueiro (2014), y Flórez (2017), señalan que el cutting o la autolesión se lleva a cabo por la necesidad de alterar estados de ánimo agobiantes, como una manera de defenderse de la angustia; en última instancia, los cortes son síntomas que encubren conflictos personales. En palabras de Mora (2013), estas lesiones se presentan como un mensaje que es preciso descifrar.

Existen otros modelos que también explican la génesis de este fenómeno entre los adolescentes, como lo es el de la mentalización, el cual sostiene que al presentarse un apego ansioso o desorganizado durante el desarrollo, el sujeto no logra mentalizar su self y, en efecto, no es capaz de sentir que es representado en la mente de otras personas como un sujeto pensante. Esto implicará dificultades para controlar tensiones emocionales o mentales, siendo por lo general los actos compulsivos de carácter autodestructivo (Sánchez, 2017) una salida o solución.

En relación con el modelo anterior, se encuentra específicamente el del apego, el cual refiere que una persona que vivió un apego inseguro o desorganizado con las figuras paternales presentará dificultades en el paso a la adultez, vivenciando durante la adolescencia, en un esfuerzo por lograr apegos seguros, síntomas principalmente relacionados con el cuerpo, los cuales tienen el propósito de intentar mejorar la visión que se tiene del yo y lograr la individuación de la personalidad (Doctors, 2013).

En esta misma línea, desde una perspectiva cercana a la teoría lacaniana, Bidaud (2010) analiza la autolesión cutánea como un sacrificio particular realizado por los adolescentes que no pueden mentalizar sus conflictos, y en el cual la sangre cristaliza el exceso de goce ignorado y persistente que se debe 
hacer salir o hacer perder a través de los cortes que el yo, en estado de frenesí, realiza en su piel para conjurar la fantasía de ser invadido por el deseo del Otro parental.

También se encuentra que el cutting puede presentarse como un ritual en que el adolescente, encontrándose solo y abrumado por el deseo del Otro, busca individualizarse o reafirmar su existencia subjetiva como un ser único, buscando separarse de ese objeto relacional de identificación con el que estableció un vínculo de amor u odio. Otra de las formas en que se presentan las autolesiones es como una práctica grupal; estas se realizan cuando se genera un decaimiento de la figura de los padres y el adolescente necesita encontrar nuevas identificaciones, por lo que puede llevar a cabo esta práctica con sus semejantes para identificarse con ellos a través de sentir que tienen un síntoma parecido (Mora, 2013).

Con respecto a la fantasía, este proceso psíquico fue descrito por Freud (1975), en su libro Los orígenes del psicoanálisis, como un medio para bloquear los recuerdos primordiales, una forma de refinarlos, sublimarlos y embellecerlos; son una construcción que se genera a partir de lo oído por el sujeto, la historia del pasado de sus padres y sus vivencias personales.

En otro de sus textos —El creador literario y el fantaseo_- Freud (1908a) señala que a medida que el sujeto crece deja de apoyarse en objetos reales para inventar juegos imaginarios que le den placer, empezando a fantasear con cosas que desea, de modo que los instintos insatisfechos o las carencias serían el origen de las fantasías. Estas se constituyen en un medio de satisfacción imaginaria de los deseos o en una vía para cambiar la realidad que es causa de insatisfacción. Sobre esto, Freud añade que, si bien las fantasías son algo privado y por lo general de lo que avergonzarse - por lo cual se prefiere mantenerlas ocultas-, pueden evidenciarse a través del discurso del sujeto que sufre y la narración de lo que él desea.

En su trabajo Fantasias histéricas y su relación con la bisexualidad, Freud (1908b) afirma que puede que estas tuvieran su origen en la consciencia como sueños diurnos, pero se tornaron inconscientes a causa de la represión por el malestar que generaban al sujeto; sin embargo, estas pueden emerger nuevamente de forma patógena, presentándose como síntomas y ataques. 
Por su parte, Žižek (1999), en su libro El acoso de las fantasías, analiza la fantasía y su incidencia en el discurso social y en la ideología contemporánea, desde una conceptualización freudo-lacaniana. En él expresa que estas son un proceso psíquico determinante para las vivencias del sujeto, puesto que, más que limitarse a ser la realización satisfactoria de deseos a nivel imaginario o solo manifestarse a través de los síntomas, funcionan como un filtro que ajusta la realidad con base en necesidades subjetivas. Es decir, la realidad se construye como una narrativa fantasmática en la que las fantasías se encuentran mediando todo comportamiento del sujeto. De tal modo, una fantasía no puede reducirse al acto puro ni a la escena imaginaria, sino que estos dos aspectos se presentan de manera complementaria, debido a que para poder actuar el sujeto necesita de fantasías que le den sentido a lo que está haciendo, lo apoyen e impulsen en correspondencia con las necesidades inconscientes que le es preciso satisfacer, tales como la del reconocimiento y el amor del Otro.

Además, basado en Lacan, Žižek (2006) señala que las fantasías constituyen una defensa del sujeto frente al núcleo traumático del enigmático y angustiante deseo del Otro, porque «lo que el Otro busca no es sencillamente a mí, sino a ese núcleo real, eso que es en mí más que yo mismo, y ese Otro está pronto a destruirme para poder extraer ese núcleo» (p. 84). Al respecto, en la articulación de los diversos desarrollos lacanianos que hace Nominé (2007), el Otro debe ser entendido no solo como la instancia simbólica del código significante, sino fundamentalmente como la pareja del sujeto en el proceso de alienación/ separación; una alteridad que escapa al dominio de este y que, en cuanto pareja caprichosa y enigmática, se constituye en el lugar del deseo, siendo además inconsistente, en la medida que el Otro no puede contestar a todo ni contestar de todo, y porque él mismo no sabe que tiene un saber.

Con base en lo anterior, y con el fin de lograr una mayor comprensión de las autolesiones cutáneas (cutting), se planteó como objetivo de estudio analizar el lugar que ocupa el Otro en la fantasía que se genera en torno a esta clase de autolesiones en una adolescente que presenta este comportamiento. 


\section{Metodología}

La investigación se basó en los lineamientos del enfoque cualitativo, el cual busca describir el fenómeno de estudio teniendo como fuente de información las experiencias subjetivas de un individuo sobre un acontecimiento (Hernández, Fernández y Baptista, 2014). En el caso particular de este estudio, se toman como ejes de indagación las vivencias de una adolescente, bajo los significantes y significados, en relación con su deseo, que ha generado en torno a estas y cómo la han llevado a realizarse cortes en la piel.

Además, para el desarrollo del proceso investigativo se siguieron los lineamientos de la investigación en psicoanálisis con propósitos cognoscitivos, que comprende dos objetivos: (1) el propósito de intensión, desde el cual se diseña un proyecto de investigación formal o académica, siguiendo un estudio sistemático, para indagar a profundidad un tema particular en función de producir nuevos conocimientos; y, (2) el propósito de extensión, en el que se busca realizar generalizaciones y emplear la teoría psicoanalítica en contextos distintos al dispositivo clínico, con el fin de generar aportes al saber psicoanalítico y posibilitar nuevos estudios (Hoyos, 2009). Así, el objetivo de intensión de la presente investigación es el estudio de la autolesión cutánea, desde un caso, que posibilite comprender los factores que causan y mantienen este comportamiento en relación con el Otro y los procesos de la fantasía, de modo que, bajo el propósito de extensión, los resultados obtenidos permitan dar lugar a réplicas o estudios similares, para afianzar o generar nuevos conocimientos sobre este tema.

Con respecto al tipo de investigación, se siguieron los lineamientos del estudio de caso, que a consideración de Martínez-Carazo (2011) consiste, con una muestra compuesta por uno o por más participantes, en llegar a una comprensión detallada del tema, teniendo en cuenta las implicaciones del estudio y el cumplimiento de las necesidades de la investigación.

Para la selección de la población participante del estudio se emplearon como criterios de inclusión: estar inscrito a la institución educativa contexto de investigación y haber presentado problemas de autolesión cutánea. Teniendo en cuenta los criterios anteriores, como muestra del estudio se 
trabajó con una (1) persona que cumplía con los requisitos expuestos, a quien se ha denominado bajo el seudónimo de "Sara", con el fin de proteger su identidad.

\section{Instrumento}

La técnica escogida para llevar a cabo la recolección de información fue la entrevista individual a profundidad, la cual se aplica a través de varias sesiones con el mismo sujeto de estudio, estableciendo conversaciones que partan de aspectos generales de la vida del participante, para ulteriormente profundizar en temáticas de interés; permite, así, obtener un conocimiento detallado del entrevistado y del fenómeno de estudio (Sandoval, 2002).

Se diseñó una entrevista semiestructurada que fue evaluada por tres pares expertos en el área del psicoanálisis para garantizar la validez de contenido de las preguntas. La versión final del instrumento contó con 61 ítems que orientaron las cuatro entrevistas realizadas durante el estudio. Este instrumento posibilitó indagar y obtener una descripción detallada de la historia de vida de la participante, permitiendo llegar a la comprensión de los significantes que ella ha generado en torno a sus vivencias y que la han llevado a realizarse autolesiones cutáneas; asimismo, permitió entender las fantasías que sostienen este acto.

\section{Procedimiento}

La recolección de datos se llevó a cabo entre los meses de mayo y junio de 2018, previo consentimiento —otorgado por parte de los acudientes- y asentimiento informado, en el cual Sara manifestó participar de manera libre y voluntaria en la investigación. Se realizaron cuatro sesiones de entrevista, cada una con una duración aproximada de 2 horas, las cuales fueron grabadas en audio y transcritas para hacer una revisión exhaustiva de las mismas. Estas entrevistas fueron realizadas en un espacio privado dentro de la institución educativa a la que pertenece la participante.

Respecto a la sistematización de los datos, estos fueron transcritos en una matriz de vaciado de información y para su interpretación se empleó la técnica 
del análisis de discurso de la escuela francesa de La Tel Quel, en particular la perspectiva de Roland Barthes. Esta consiste en extraer fragmentos o lexías de lo narrado por el participante, resaltando factores afectivos y relacionales (Barthes, 2004), con el fin de rearticularlos y contrastarlos con los fundamentos teóricos, en dirección a realizar interpretaciones para llegar a un entendimiento de las formaciones del inconsciente (Carmona, 2011).

La elección de esta técnica se justifica por la fecunda relación teórica que mantuvo Barthes con el psicoanálisis — principalmente lacaniano- a través de su obra y en particular en sus libros El placer del texto (Barthes, 1974) y Lo obtuso y lo obvio (Barthes, 1986). En el primero diferencia el texto de placer y el texto de goce; en el segundo propone el denominado sentido obtuso de la significancia, el cual está vinculado con los juegos de palabras y las bromas, por declinar la significación normalizada en una ampliación del sentido que libera goce y revela lo oculto. Este concepto podría relacionarse con el equivoco significante, destacado por Lacan (2012) como una de las formas privilegiadas de la interpretación analítica.

De ahí que la preferencia metodológica que tuvo el semiólogo francés por el fragmento de texto que llama lexía, más que por la oración como unidad de análisis de sentido completo, lo acerca al trabajo con indicios y fragmentos, propio de la praxis psicoanalítica, y lo aleja de la escuela de Van Dijk, cuya técnica de análisis de discurso está más ligada al cognitivismo. Asimismo, se distancia de escuelas como la Lingüística crítica (Fowler, Kress, Hodge y Trew, 1983) y la Gramática sistémico funcional (Halliday, 1982), que, si bien se adscriben a la corriente del Análisis crítico del discurso, toman como unidad de análisis la oración en cuanto unidad de significación completa.

Debido a lo anterior, para dar cumplimiento al objetivo de investigación, las lexías o fragmentos discursivos se ubicaron en una matriz compuesta por dos categorías emergentes: El origen de las autolesiones cutáneas y La significación del corte en la fantasía, las cuales permitieron llegar a un entendimiento del lugar que ocupa el Otro en la fantasía generada en torno a las autolesiones cutáneas.

Por último, la investigación tuvo en consideración los aspectos éticos y normativos expresados por los lineamientos de la Organización de las $\mathrm{Na}$ ciones Unidas para la Educación, la Ciencia y la Cultura (Unesco, 2005), de 
la Declaración universal sobre bioética y derechos humanos y de la ley 1090 de 2006, por la cual se reglamenta el ejercicio de la profesión de psicología, se dicta el Código deontológico y bioético y otras disposiciones. Se contó con la aprobación del consentimiento y asentimiento informado por parte del comité de ética de la Universidad de Nariño, y, en correspondencia con estos documentos, se respetó la confidencialidad de la participante y garantizó su bienestar.

\section{Resultados y discusión}

Sara es una adolescente de 16 años, estudiante de décimo grado de bachillerato, que vive con su madre y su padrastro. Durante las entrevistas a profundidad se presenta recurrentemente en su discurso el significante de soledad, descrito como la carencia de afecto y la falta de atención por parte de su familia. Señala que siempre ha sentido — desde su infancia hasta la actualidad— no ser escuchada por sus seres queridos, llegando al punto de sentirse ignorada e incluso rechazada por ellos.

En el relato de la historia de vida de Sara se presentan eventos que, como ella lo dice, le han dejado marcas afectivas negativas; entre estas, la separación de su madre durante sus primeros años de vida, el rechazo de su padre en su adolescencia, y el poco afecto y atención que ha recibido de su madre en la actualidad. Todo ello, aunado a diferentes crisis emocionales generadas por discusiones familiares, desencadenó la práctica furtiva de las autolesiones cutáneas, con la que manifestó haber sentido que lograba olvidarse de sus problemas y obtener tranquilidad.

Para entender este comportamiento, y su función o satisfacción a nivel de la fantasía, fue necesario analizar algunos fragmentos del discurso, o lexías, que dan cuenta de su origen y de las significaciones que lo han mantenido.

\section{El origen de las autolesiones cutáneas}

$\mathrm{Al}$ momento en que se le indaga a Sara cuándo fue la primera vez que se realizó una lesión cutánea, responde: 
Fue porque tuve una pelea con mi mamá o mi papá, no me acuerdo, tuve una pelea y no sé, me dio por, o sea, estaba tan estresada y empecé... y ahí... a veces me altero mucho y empecé a tirar todo y al estar tirando cosas encontré pues una cuchilla y no sé, al momentico solamente la pasé y ya y después ya vi que estaba sangrando.

Lo enunciado por Sara responde a lo mencionado por Flores et al. (2013) respecto a que entre las causas de esta situación se encuentran los eventos estresantes relacionados habitualmente con las dificultades familiares. Es un punto inicial de interés para comprender lo que significa para Sara el Otro parental y su relación con las autolesiones cutáneas; este análisis va en la dirección de lo enunciado por Lacan respecto al papel dominante que posee el Otro como sede previa del puro sujeto del significante, dado que sostiene en él la posición de dominio antes incluso de llegar a la existencia, como Amo absoluto (Lacan, 1980).

Con respecto a la génesis de las autolesiones de Sara, a lo largo de su discurso se denota que esta es consecuencia de las diferentes dificultades familiares que ha vivido fundamentalmente con su Otro parental, o planteado de un modo más preciso, de los significantes y significados que ella ha elaborado en torno a estas dificultades. $\mathrm{Al}$ indagar sobre su historia familiar expresa:

Es que yo he tenido como una vida muy... sola, ¿sí me entiende?, porque, pues, nunca tuve a mi mamá o alguien que se preocupara, o sea, mi papá siempre me quiso dar como lo material, él se preocupaba por trabajar y darme cosas, pero nunca se fijó en que lo que yo necesitaba, era como un afecto o que se acercaran a preguntarme cómo estaba, que qué sentía.

Lo enunciado por Sara se analiza a la luz de lo planteado por Soler (2007) cuando destaca que uno de los fenómenos que se presentan en la actualidad es la precariedad de los vínculos entre los sujetos, siendo un caso la carencia de lazos familiares, lo cual genera en los individuos un efecto de sinsentido sobre su existencia o su vida cotidiana, desencadenando diferentes formas de malestar subjetivo.

Además, cabe señalar que dicho sinsentido se sustenta, a su vez, en el hecho de que la sociedad capitalista posmoderna busca repararlo, paradójicamente, a través de los objetos plus de goce; objetos con los que el sujeto compensa la 
pérdida del gran goce mítico causada por su inserción en el lenguaje y la cultura y que la actual sociedad intenta replicar desde la manufactura industrial (Lacan, 1968). Bien dice Sara: "Mi papá siempre me quiso dar como lo material, él se preocupaba por trabajar y darme cosas, pero nunca se fijó en que lo que yo necesitaba”. En torno a esto, Soler (2007) reitera que los objetos no hacen lazo social; por tanto, como se manifiesta en el caso, el hecho de recibir objetos materiales no genera una significación de afecto, debido a que en estos no hay un discurso que inscriba al sujeto en lo simbólico y en el reconocimiento del Otro, generando, en efecto, una sensación de soledad y desamparo.

\section{Añadido a lo anterior, Sara sostiene:}

Yo solamente quería a alguien que me escuchara y me decían que yo no he sufrido así como otra gente para que yo esté así, o sea, que todo lo que yo digo es mentira, que mis sentimientos o algo así son falsos.

Así, se evidencia que ella se siente como un sujeto en falta al no ser reconocida por el Otro (Lacan, 1962), siendo este el principal factor que incita al comportamiento autolesivo: la falta de reconocimiento apreciada como la poca aceptación dada por parte del Otro.

Por otra parte, Sara resalta que, como un evento significativo en su vida, en su infancia vivía con su padre, pero durante su pubertad este la envió a vivir con su madre a otra ciudad; hecho que le hace guardar rencor hacia él.

Pues sí, rencor hacia los papás de que uno, pues, de que no lo dejan decidir a uno, de que lo pasan a cualquier lado sin pensar en lo que uno quiere, en lo que uno siente, como que te pasan de una ciudad a otra siempre y para toda la vida; (...) lo que te aburre eso, sentir como que te da la espalda tu propio papá, porque él no quiere llevarte a vivir con él, entonces te sientes como rechazada, como rabia, y ver como que él está con tus otras hermanas, pero que no contigo; eso da más rabia.

Lacan (1962), en el seminario x: La angustia, señala que cuando el sujeto es rechazado por el Otro, no por ser quien es como ser en falta, sino como un objeto residual, pierde su lugar de sujeto, lo que desencadena la angustia; al respecto Flórez (2017) explica que los cortes permiten obtener un sentido para la existencia subjetiva en relación con el Otro. Asimismo, Dartiguelongue (2014) señala cómo, ante esta pérdida de significación sobre la identidad 
del yo que implica el rechazo, los cortes permiten realizar un proceso de separación del Otro o de constitución del individuo como sujeto para dejar de estar posicionado simbólicamente como un objeto de un deseo hostil de rechazo. Así, el corte asume una función de separación análoga a la del objeto transicional; es decir, el objeto que le permite al ser separarse de la alienación del Otro para poder constituirse como sujeto. De este modo lo fundamenta Lacan en el seminario x (1962), donde conceptualizó al objeto transicional como objeto cesible, constituido en la función de separación, que, a propósito del objeto oral, comprendía — clásicamente- el objeto en juego en la ruptura del vínculo con el Otro. En este mismo sentido, para Manca (2011) la autolesión posibilita al sujeto atacar su propio límite, de tal forma que el dolor y la subsecuente herida causada por la autolesión pueden ser vistos como un proceso ritualizado, con el que el individuo reconfigura a su gusto las fronteras entre sí mismo y su mundo alrededor.

En relación con lo anterior, se resalta que para Sara la vida familiar con el Otro materno presentó la misma falta de afecto y atención, puesto que al indagar sobre este vínculo expresa:

Mi mamá, pues, casi no hablamos porque trabaja y pues cuando hablo es por las noches o no le hablo, si no que entro a la habitación de ella y como que me acuesto al lado de ella, pero no hablamos (...) Yo a ella la quiero mucho, sino que no se lo demuestro, yo solamente intento como no hacerla enojar, porque ella a veces se enoja por todo (...) Yo a ella, yo la considero una mujer, sí, trabajadora, sí, pero nunca, o sea, de que ella lucha bastante, ella se mata trabajando, pues, por mí, yo sé, pero ella hace lo mismo que mi papá hacía, solo trabajan y trabajan.

Al profundizar sobre este sentimiento de soledad y qué sentía al no ser escuchada, dice:

Ya no me importa si alguien escucha lo que yo tengo, es más, si tengo algo que tengo que desahogar, lo hago de otra forma (...) ya no tengo nadie quien me escuche, pues me vale y ya yo veré qué hago yo ahí.

Puede identificarse cómo a falta de Otro que otorgue sentido, el sujeto queda solo, reducido a su propio cuerpo y expuesto a los impactos de lo Real, presentándose el traumatismo en la vida cotidiana, causado por cualquier 
evento adverso que la persona no puede enfrentar; en el caso de Sara, los conflictos familiares que le evocan la soledad y la impulsan a realizar comportamientos destructivos. Al respecto, Gallo (2003) señala que los problemas contemporáneos que se presentan en relación con las vivencias subjetivas que supone la adolescencia son evidencia del fracaso que tiene el amor, el yo y la institución familiar para responder adecuadamente a las exigencias del medio social y regular la agresividad.

Sobre este punto es necesario resaltar lo expresado por Flesler (2011) referente a cómo en la adolescencia se configuran disposiciones subjetivas que dirigen a una tendencia de habituar una reacción, entre diversas maneras, ante lo real del goce, lo cual no tiene su explicación en la edad cronológica del individuo, sino que depende de los recursos simbólicos tomados del Otro familiar; por tanto, al no contar durante este tiempo con recursos que le permitan resolver sus dificultades de forma satisfactoria, el sujeto efectuará actos que lo desborden y que, en última instancia, son un pedido al Otro de simbolización.

\section{La significación del corte en la fantasía}

Es preciso retomar el significado que Sara otorga en su discurso a la falta de afecto que existió por parte de sus padres y que le ha causado un sentimiento de soledad, en cuanto valora que no es objeto de deseo del Otro ni de su amor, desencadenado el malestar que la impulsa a realizarse las autolesiones cutáneas. Para poder dar explicación a este hecho es necesario analizar la fantasía tras los cortes que Sara se realiza a partir de la intención con la cual los hace y la función subjetiva que les es dada.

Sara durante las entrevistas dice que a partir de las dificultades familiares que vive ha presentado ideación suicida; señala:

Pues no sé, o sea, yo muchas veces intenté como tirarme de... pero eso no lo hacía porque no sé; o sea, como que intentaba, pero como, o sea, como yo creo en Dios; no sé, yo decía: "No es lo justo". A veces también intenté tomarme pastillas; una vez lo iba a hacer, pero mi hermana entró a mi pieza y me tocó botarlas y no las pude recuperar después. Otra vez iba a hacerlo con las pastas y justo cuando me llamaron por teléfono y era mi mejor amiga, y ella es la que sabe lo que a mí me pasa, entonces yo dejé las pastas allí y me fui a contestar y ya cuando ella me habló 
me ayudó tanto que me desahogué y solté todo eso, que ya cuando regresé solo boté las pastas. Nunca pude hacerlo, no por falta de, de cómo se dice, de valentía, solo porque no sé, algo pasaba, justo algo pasaba para no hacerlo.

Con base en esto puede plantearse que la acción de realizarse autolesiones cutáneas no puede considerarse realmente un pasaje al acto, dado que según Lacan (1962) este se da cuando existe una ruptura de la estructura fantasmática del sujeto, dejando como única opción de reacción el acto real, agresivo y salvaje. Se propone, entonces, que el acto de Sara sigue mediado por su fantasma y el suicidio no es realmente su intención; por eso seńala: "algo pasaba, justo algo pasaba para no hacerlo".

Además, en ese fantasear con hacerse daño a sí misma puede verse cómo ella intenta responder a la pregunta: ¡cuál es el deseo del Otro?

\begin{abstract}
Yo siempre pensaba lo malo o pensaba en hacerme atropellar, o en mi mente, de tanta cosa, empecé a imaginar cómo era la muerte o cómo me podría pasar o cómo haría para que me llevaran al hospital y estar en coma para que todas las personas que no me llegaron a escuchar pudiesen como que reaccionar, reflexionar y decir: "Bueno, ella no está", o algo así. Yo me imaginaba cosas, como hacerles, prácticamente hacerles sufrir si es que ellos me querían de verdad, yo quería verlos sufrir como yo lo hacía, como yo me sentía mal, quería que ellos, quería verlos sentirse mal y quería verlos llorar; o sea, eso era como una rabia, un coraje con las personas, que quería verlos mal para que vean cómo se siente y para que vean que no es porque uno quiere, es porque le pasa.
\end{abstract}

Es decir, la imagen fantaseada de sí misma en estado de enfermedad o invalidez se constituiría en la forma de lograr la atención anhelada, convirtiéndose en el objeto del deseo acogedor del Otro, de modo que puede referirse allí el velo denominado por Žižek (1999), entre los siete que propone respecto a la fantasía, como intersubjetividad; este indica que a cada sujeto en su fantasía le es necesario vislumbrar cómo debe ser, actuar o hacer para poder encontrar la forma de relacionarse con el Otro y poder constituirse como objeto de su deseo. De este modo, en el caso de Sara el suicidio no constituye una forma de dar cumplimiento a este propósito; como ella refiere:

Y, pues, nunca llegué a hacerlo. Fue porque no fue el momento o porque empecé a reflexionar en mí misma que no le daría gusto a la gente; otras veces sí intenté 
hacerlo porque, pues, como te digo, yo quería ver a la gente sentirse igual, pero, pues, nunca se pudo, por eso ahí fue que más que todo empezaron las cortadas, porque no me mato, solamente me tranquilizo de otra forma.

Se puede afirmar que, en su fantasía, las autolesiones constituyen el medio para ubicarse a sí misma en un estado en el que pueda atraer la mirada del Otro o ser digna de su amor, por lo cual también cabe aseverar que las autolesiones en la piel son una demanda, y como lo indica Lacan (1958), en los avatares de la demanda siempre hay una exigencia de reconocimiento del Otro, que en el trasfondo es una exigencia de amor.

Por lo anterior, puede comprenderse cómo los cortes en la piel son un acting out, dado que como lo señala Apolinario (2010), este se relaciona estrechamente con la pulsión escópica, en función de la cual el sujeto, como en el caso de Sara, hace algo con la finalidad de atraer la mirada del Otro, llamando su atención con un acto y no a través de las palabras. Con ello se encuentra una forma de relacionarse con el Otro, lo cual no le sería posible a través del suicidio. Además, hay que hacer notar nuevamente que Sara refiere no sentirse escuchada. En su definición de acting out, Dylan (2007) plantea que este aparece cuando el Otro se hace el sordo y es imposible darle un mensaje con palabras, por lo que el sujeto se ve compelido a comunicarle con acciones un mensaje oculto, que él ni siquiera es capaz de comprender o, incluso, de conocer su contenido. Del mismo modo lo plantea Lacan (1962): el acting out es fundamentalmente algo, en el comportamiento del sujeto, que se muestra, pero donde lo mostrado se exhibe esencialmente como distinto de lo que es; al respecto, en lo relatado por Sara ella resalta: "Yo lo hago y lo hago y a lo último es que yo digo: ‘¿Por qué lo hice?’ Yo ni me entiendo por qué hago las cosas (...)".

La demanda que Sara realiza también puede verse en otra de las fantasías que ella hace del acto de las autolesiones cutáneas. Al momento en que se le indaga acerca de cómo cree que su padre reaccionaría si se enterase de su práctica autolesiva, dado que él aún no sabe sobre esta, responde:

Pues no sé, es que depende si él lo tomaba, o sea me daría miedo que pensara que era por llamar la atención y yo no es por llamar la atención, porque si yo quisiera llamar la atención dejaría que todos se dieran cuenta, pero no. 
En esta frase ella no responde a la pregunta que se le realiza sobre la reacción del padre, dado que dice: "Depende si él lo tomaba", lo cual en su significado es diferente a declarar: "Depende de cómo lo tomaba", pues en la enunciación realizada por Sara se puede resaltar que su interés no recae en la posible reacción negativa o positiva del padre, sino en la posibilidad de que este tomara interés en el problema que ella presenta; en última instancia, que tome interés en ella. Como se mencionó anteriormente, la fantasía es el medio por el que el sujeto debe idear cómo constituirse en el objeto de deseo del Otro. En consecuencia, las lesiones para Sara comprenden esta posibilidad. Lo anterior alude a la petición imaginaria del sujeto referente a la oposición entre el objeto de necesidad que el Otro tiene para dar siempre, y el objeto de amor que el Otro no posee y que refiere al falo imaginario (Lacan, 1960).

Respecto a la experiencia de las autolesiones, al preguntarle a Sara qué sentía al realizarse los cortes en la piel, responde:

Tranquilidad al hacerlo; después ya me sentía como más tranquila, como uno no tiene a alguien que lo escuche, entonces eso es como... escucharse a uno mismo, como hacerlo uno mismo, hacerlo, tranquilizarse a uno mismo de una forma fácil.

En este fragmento es de especial interés el significante de escuchar, debido a que en repetidas ocasiones ha referido que es esto de lo que ha carecido por parte de su familia; por tanto, se evidencia cómo los cortes se acompañan de una fantasía mediante la cual se evoca a un Otro que escucha. Sobre este respecto, Žižek (1999) señala que una de las funciones de la fantasía, denominada Tras la caída, es realizar la instauración de la ley o una instauración misma del Otro a nivel de lo imaginario; es decir, mediante la fantasía se busca que este se haga presente y otorgue eso que representa, bien sea su ley, reproche, castigo o, en este caso, amor.

Lo anterior es consecuente con lo expresado por Sara al seguir indagando sobre el alivio que siente después de realizarse los cortes en la piel; lo describe de la siguiente manera: "Como cuando uno está llorando y a uno le dan un abrazo, como que ya uno está sintiendo que alguien lo está apoyando, algo así como que uno deja de llorar". 
Esta lexía de su discurso permite corroborar que los cortes que hace en su piel representan en su fantasía un medio para suplir imaginariamente la falta de afecto que ha sentido por parte del Otro parental; por lo tanto, se puede decir, siguiendo a Žižek (1999), que los cortes más que devenir una satisfacción pulsional, son un ritual que le permiten hacer un llamado al Otro, siendo esta la fantasía que sostiene su comportamiento autolesivo.

Para lograr un mayor entendimiento de la función del Otro en esta fantasía articulada a las autolesiones es preciso retomar lo dicho por Sara, al inicio de las entrevistas, frente al motivo por el cual se realizó por primera vez un corte en su piel: "Fue porque tuve una pelea con mi mamá o mi papá (...)". Tal como se mencionó anteriormente, sus autolesiones no son provocadas por las peleas o las discusiones con sus padres en sí mismas, sino por lo que representan a nivel de su inconsciente; es decir, estas la hacen sentir que no es deseada como un objeto de amor por el Otro parental o reconocida por él como sujeto. En efecto, este comportamiento aparecerá siempre que ella sienta que no es reconocida como tal, pues así lo refiere en otros fragmentos de su discurso.

En una de las entrevistas señala haber tenido el día anterior una discusión con su madre; al preguntar qué sintió a causa de esto, responde:

\footnotetext{
No sé, en ese momento empecé a imaginar tantas cosas que yo dije que si ella me llega a pegar, mi única reacción sería correr a alguna parte, buscar algo con qué hacerlo, desahogarme (...) si me desahogo [desahogo refiere a realizarse autolesiones cutáneas], ya no tengo que pelear con ella, ni pelear ni nada, y llegué a pensarlo y fue más que todo por ella que no lo hice, porque ella me habló y entonces yo obviamente estaba muy enojada y no le hice caso. Al llegar a la casa a mí ya se me había como olvidado de hacerlo porque ya estaba bien con ella; ya estaba bien, ella se había disculpado, pero, pues, yo solo pensaba en desahogarme y hacerme corte muy fuerte, pero gracias a ella no lo hice, porque si ella no hubiera reaccionado, yo creo que sí lo hubiera hecho, o sea, como me conozco: yo sé que lo haría.
}

De lo anterior se pueden resaltar diferentes lexías, como el caso de: "Si ella me llega a pegar mi única reacción sería correr a alguna parte, buscar algo con qué hacerlo, desahogarme", respecto a la cual es necesario enfatizar la fantasía que Sara realiza sobre la posible reacción de su madre ("Si ella me llega a pegar") como un acto agresivo, distinto a lo que hubiera sido la idea: "Si ella me llega a regañar", el cual reduce a los sujetos — tanto al que agrade como 
al agredido- en cuerpos, y, por tanto, en objetos, donde no hay cabida para la verbalización. Se presenta una vez más el hecho que es causa del malestar de Sara: no ser reconocida como un sujeto. Ahora bien, Sara apunta: "Si me desahogo ya no tengo que pelear con ella", expresión que adquiere sentido a la luz de las interpretaciones realizadas anteriormente frente a cómo los cortes son un medio para llamar al Otro, obtener su reconocimiento y lograr así posicionarse como sujeto (Soler, 2007), encontrándose allí la razón del bienestar que siente a través de las autolesiones; es decir, la posibilidad de que al ubicar en la escena el corte, el Otro se acerque a ella como sujeto y no como objeto.

No obstante, cuando Sara señala: "Yo solo pensaba en desahogarme y hacerme cortes muy fuerte, pero gracias a ella no lo hice, porque si ella no hubiera reaccionado, yo creo que si lo hubiera hecho", lo primordial del hecho es que al disculparse la madre, no por el acto del perdón, sino por el acto de dirigir su palabra hacia Sara, la reconoce como un sujeto en falta, debido a que, como lo menciona Dylan (2007), el lenguaje es el medio que posibilita a los individuos obtener el reconocimiento del Otro y constituirse como sujeto. Esto es lo que Sara desea y, consecuentemente, el acto de la autolesión cutánea no tiene lugar, puesto que ha perdido su función a nivel de la fantasía.

\section{Conclusiones}

En consideración del objetivo de investigación, los resultados permiten corroborar que, si bien entre las causas que llevan a la adolescente a realizarse cortes en la piel, se encuentra el deterioro de la relación subjetivante con el Otro parental, es factible determinar que este no es un acto que el sujeto realice netamente para liberarse de su malestar emocional, generar autocastigo, reforzar su autoimagen o identidad personal, sino que posee un sentido inconsciente que es construido a partir de la historia de cada persona.

En comparación a lo que otros autores han afirmado frente a la autolesión como un medio para separarse del Otro, el análisis aquí realizado permite aseverar que el cutting también puede encontrar su génesis en otras funciones que se develan en la fantasía que acompaña a este acto; en este caso particular, es 
un medio para invocar imaginariamente al Otro y buscar satisfacer las demandas de reconocimiento y amor que este no acoge. Por lo tanto, la autolesión se constituye en un medio para poder establecer un vínculo imaginario con el Otro. En suma, en este caso se puede afirmar que la autolesión, además de constituir una forma de separación del deseo hostil del Otro parental, también se constituye en un acting out, a través del cual el sujeto dirige inconscientemente un llamado al Otro para que satisfaga, como ya fue planteado, su demanda de amor y reconocimiento subjetivante.

Con base en lo anterior, las fantasías que el sujeto asocia a sus actos constituyen el recurso psíquico a través del cual la autolesión adquiere para él el sentido de convocar la mirada, la palabra y el amor subjetivante del Otro parental que se niega a escuchar y acoger el ser en falta del sujeto.

En coherencia con el objetivo de intensión del estudio, se resalta que a través del trabajo realizado a partir de un caso único $(\mathrm{N}=1)$ se ha logrado analizar el lugar que ocupa el Otro en la fantasía que se genera en torno a las autolesiones cutáneas (cutting) en una adolescente que presenta este comportamiento; no obstante, si bien los hallazgos de este trabajo brindan una base teórica de las causas de la autolesión cutánea en adolescentes, desde la perspectiva de la fantasía, esta responde a las particularidades del caso estudiado, por lo que, en relación con el objetivo de extensión, se recomienda realizar réplicas de este estudio o continuar con investigaciones que tengan como foco de interés los procesos de la fantasía en torno a los comportamientos autolesivos de los adolescentes, de modo que se afiancen los resultados aquí encontrados o que se posibilite obtener nuevas perspectivas de cómo y cuáles fantasías sostienen este tipo de comportamiento.

\section{Referencias}

Albores-Gallo, J., Méndez-Santos, J., Xóchitl-García, A., Delgadillo-González, Y., Chávez-Flores, C., y Martínez, O. (2008). Autolesiones sin intención suicida en una muestra de niños y adolescentes de la ciudad de México. Actas Esp Psiquiatr, 42(4), 159-68. Recuperado de https://actaspsiquiatria.es/repositorio/16/90/ ESP/16-90-ESP-159-168-346514.pdf 
Apolinario, C. (2010). Acting out y pasaje al acto entre el acto y la enunciación. En G. Gómez, (ed.), Acto, pasaje al acto y acting out en psicoanálisis (pp. 65-78). Bogotá: Mavarac.

Baetens, I., Claes, L., Muehlenkamp, J., Grietens, H., y Onghena, P. (2011). Non-suicidal and Suicidal Self-Injurious Behavior Among Flemish Adolescents: A Web-Survey. Archives of Suicide Research, 15(1), 56-67. doi: https://doi.org/10. 1080/13811118.2011.540467

Barthes, R. (1974). El placer del texto. México D. F.: Siglo xxi.

Barthes, R. (1986). Lo obtuso y lo obvio: imágenes, gestos, voces. Buenos Aires: Paidós.

Barthes, R. (2004). S/Z. Buenos Aires: Siglo xxi.

Bidaud, E. (2010). Reflexiones sobre la clínica por sangrado provocado. En: A. Gonzaga y C. Weinber (eds.), Psicoanálisis de Trastornos Alimentares (pp. 16-27). São Paulo: Primavera Editorial.

Carmona, D. (2011). El asunto del método en la investigación psicoanalitica. Medellín: Imprenta Universidad de Antioquia.

Carvajal, H. E., Arancibia, B., Díaz, J. R., Mendoza, H., y Salgueiro, G. (2014). Autolesionismo: síndrome de cutting. Archivos bolivarianos de medicina, 22(90), 50-55. Recuperado de http://www.revistasbolivianas.org.bo/pdf/abm/v22n90/ v22n90a09.pdf

Dartiguelongue, J. (2014). Sintomas contemporáneos: sobre la práctica del cutting, cortes sobre el cuerpo. Jornadas Jacques Lacan y la Psicopatología. Psicopatología Cátedra II - Universidad de Buenos Aires, Buenos Aires.

Declaración Universal sobre Bioética y Derechos Humanos. Unesco, 19 de octubre de 2005. Recuperado de http://portal.unesco.org/es/ev.php-URL_ ID=31058\&URL_DO=DO_TOPIC\&URL_SECTION=201.html

Dylan, E. (2007). Diccionario introductorio de psicoanálisis lacaniano. Buenos Aires: Paidós SAICF.

Doctors, S. (2013). Apego-individuación: como una visión relacional del desarrollo psicológico normal clarifica la formación de síntomas en la adolescencia. Revista electrónica de psicoterapia, 7(3), 483-494. Recuperado de https://www.psicoterapiarelacional.es/Portals/0/eJournalCeIR/V7N3_2013/01_Doctors_Apego-Individuacion_CeIRV7N3.pdf

Favazza, A. R. (1998). The Coming of Age of Self-Mutilation. Journal of nervous and mental disease, 186(5), 259-268. doi: https://doi.org/10.1097/00005053199805000-00001 
Flesler, A. (2011). El niño en análisis y las intervenciones del analista (2. $\left.{ }^{\mathrm{a}} \mathrm{ed}.\right)$. Buenos Aires: Paidós.

Flores, R. E. U., Hernández, C. C., Navarrete, K. P., y Figueroa, G. V. (2013). Frecuencia de autolesiones y características clínicas asociadas en adolescentes que acudieron a un hospital psiquiátrico infantil. Salud mental, 36(5), 417-420. doi: https://doi.org/10.17711/SM.0185-3325.2013.052

Flórez, S. (2017). Cutting o cortes en la piel: una práctica que habla. Revista Poiésis, (32), 94-100. Recuperado de https://www.funlam.edu.co/revistas/index.php/ poiesis/article/view/2302/1736

Fowler, R., Kress, G., Hodge, B., y Trew, T. (1983). Lenguaje y control. México D. F.: Fondo de Cultura Económica.

Freud, S. (1975). Los orígenes del psicoanálisis (6. ${ }^{\mathrm{a}}$ ed.). Madrid, España: Alianza Editorial.

Freud, S. (1908a). El creador literario y el fantaseo. En J. Etcheverry (trad.), Obras completas (Vol. IX, pp. 127-136). Buenos Aires: Amorrortu Editores.

Freud, S. (1908b). Las fantasías histéricas y su relación con la bisexualidad. En J. Etcheverry (trad.), Obras completas (Vol. IX, pp. 141-148). Buenos Aires: Amorrortu Editores.

Gallo, H. (2003). Pareja y familia clinica de la diferencia sexual. Medellín: Editorial Universidad de Antioquia.

Greydanus, D. E. y Omar, H. A. (2017). Self-Cutting and Suicide: A Review. International Journal of Child Health and Human Development, 10(4), 391-396.

Halliday, M. A. K. (1982). El lenguaje como semiótica social: la interpretación social del lenguaje y el significado. México, D. F.: Fondo de Cultura Económica.

Hernández, R., Fernández, C., y Baptista, P. (2014). Metodología de la investigación. México D. F. México: McGraw-Hill.

Hoyos, J. (2009). Perspectivas de la investigación psicoanalitica en Colombia. Medellín: Imprenta Universidad de Antioquia.

Lacan, J. (1958). El seminario de Jacques Lacan. Libro 6 El deseo y su interpretación, 1958-1959. Buenos Aires: Paidós.

Lacan, J. (1960). Seminario VIII. La transferencia. Buenos Aires: Paidós

Lacan, J. (1962). El seminario de Jacques Lacan. Libro 10 La angustia, 1962-1963. Buenos Aires: Paidós. 
Lacan. J. (1968). Seminario XVI. De un Otro al otro. Buenos Aires: Paidós.

Lacan, J. (1980). Subversión del sujeto y dialéctica del deseo en el inconsciente freudiano. En T. Segovia (trad.), Escritos I. México D. F.: Siglo xxi.

Lacan, J. (2012). Otros escritos. Buenos Aires: Paidós.

Ley 1090 de 2006, por la cual se reglamenta el ejercicio de la profesión de Psicología, se dicta el Código deontológico y bioético y otras disposiciones. Congreso de Colombia, Bogotá D. C., Colombia, 6 de septiembre de 2006.

Manca, M. (2011). Agresiones al cuerpo en la adolescencia: ¿̇redefinición de los límites del cuerpo o desafío evolutivo? Psicoanálisis: Revista de la Asociación Psicoanalitica de Buenos Aires, 33(1), 77-88. Recuperado de http://www.psicoanalisisapdeba.org/descriptores/adolescencia/agresiones-al-cuerpo-en-la-adolescencia-redefinicion-de-los-limites-del-cuerpo-o-desafio-evolutivo/

Martínez-Carazo, P. C. (2011). El método de estudio de caso. Estrategia metodológica de la investigación científica. Revista cientifica Pensamiento y Gestión, (20), 165-193. Recuperado de http://rcientificas.uninorte.edu.co/index.php/pensamiento/article/viewFile/3576/2301

Mayer, P. A., Morales, N., Figueroa, G., y Ulloa, R. E. (2016). Adolescentes con autolesiones e ideación suicida: un grupo con mayor comorbilidad y adversidad psicosocial. Salud pública de México, 58(3), 335-336. doi: http://dx.doi. org/10.21149/spm.v58i3.7893

Ministerio de Salud (2018). Boletín de salud mental. Conducta suicida (Subdirección de enfermedades no transmisibles). Bogotá D. C.: Ministerio de Salud.

Mora, K. (2013). Cortes en el cuerpo: respuesta sintomática en el adolescente y su incidencia en la institución educativa (Tesis de maestría). Universidad Católica de Santiago de Guayaquil, Ecuador.

Nominé, B. (2007). Clínica Psicoanalítica. Cuadernos de una enseñanza itinerante. Bogotá: Mavarac.

Sánchez, T. (2017). Autolesión y mentalización: viaje a través de las heridas. Clinica e Investigación Relacional, 11(2), 337-351. doi: http://dx.doi.org/10.21110/19 882939.2017.110208

Sandoval, C. (2002). Programa de especialización en teoría, métodos y técnicas de investigación social. Investigación cualitativa. Bogotá: ARFO.

Soler, C. (2007). De un trauma al Otro. Medellín: L. Viecoe Hijas.

Ulloa, R. E., Hernández, C. C., Paniagua, K., y Figueroa, G. V. (2013). Frecuencia de autolesiones y características clínicas asociadas en adolescentes que acudieron a 
[202] Andrés Felipe Rojas-Zapata, Orlando Lenin Enríquez-Eraso, Gilberto Carvajal-Guzmán

un hospital psiquiátrico infantil. Salud mental, 36(5), 417-420. Recuperado de https://www.medigraphic.com/pdfs/salmen/sam-2013/sam135j.pdf

Zamorano, C. y Rojas, C. (2017). Adolescent Self-Cutting: An Embodiment of the Unsaid. Australian and New Zealand Journal of Family Therapy, 38(3), 317-328. doi: https://doi.org/10.1002/anzf.1240

Žižek, S. (1999). El acoso de las fantasías. Buenos Aires. Siglo xxı.

Žižek, S. (2006). El desvío de lo real. En Autor, El títere y el enano: el núcleo perverso del cristianismo. Buenos Aires: Paidós. 